\title{
Design for Deconstruction in the Design Process: State of the Art
}

\author{
Jouri Kanters
}

Energy and Building Design, Lund University, P.O. Box 118, 22100 Lund, Sweden; jouri.kanters@ebd.lth.se; Tel.: +46-46-2227236

Received: 28 September 2018; Accepted: 2 November 2018; Published: 6 November 2018

\begin{abstract}
Stricter building regulations have resulted in the construction of buildings with a low energy use during the operation phase. It has now become increasingly important to also look at the embodied energy, because it might, over the lifespan of the building, equal the energy used for operating the building. One way to decrease the embodied energy is to reuse building materials and components or to prepare the building for deconstruction; a term called design for deconstruction (DfD). While design for deconstruction has showed environmental, social, and economic benefits, hardly any building designed and built today is designed for deconstruction. The aim of this literature review is to understand the state-of-art of design for deconstruction and how it affects the design process. In most of the literature, general construction principles are specified that promote the design for deconstruction and focus on (a) the overall building design, (b) materials and connections, (c) construction and deconstruction phase, and (d) communication, competence, and knowledge. Furthermore, the reuse potential of specific building materials is discussed, as well as the available tools for DfD. Additionally, the current barriers for DfD as specified by the literature show lack of competence, regulations, and other related elements.
\end{abstract}

Keywords: design for deconstruction; architecture; design process

\section{Introduction}

Buildings currently account for a significant part of the total energy use in the world; for example, in Sweden, this share is $40 \%$ [1]. Planning for more energy-efficient buildings with a low environmental impact is a key factor in the transition towards a sustainable society. European member states have toughened requirements on the allowed energy consumption for the operation phase in new buildings. It has, however, become increasingly important to ensure that buildings have a low embodied energy, since it could equal the same amount of energy as the building's operational energy use for 50 years [2]. The construction of buildings is also very material intensive; $40-50 \%$ of all extracted raw materials are transformed into building products [3]. At the same time, construction and demolition waste stands for a significant share of the total waste stream, for example, 30\% in Sweden (omitting mining waste) [4]. This source of material is rarely used for reuse as building materials.

In the early design and planning process of new buildings, volumes and materials are directly or indirectly chosen that will affect the building's function, its appearance, but also the maintenance of the building and the environmental impact of these materials. What is hardly discussed during the design and planning process is how, at the end-of-life (EoL) phase, the building and its materials can be deconstructed or disassembled in order to design out waste or minimise the waste stream. Designing out waste will not only reduce the total environmental impact of a building, but it also has social and economic benefits.

$\operatorname{DfD}(\mathrm{DfD})$ is a method where a design team designs a building that facilitates not only adaptation and renovation, but also the reuse of building materials and components. The environmental benefits 
are the preservation of embodied energy, the reduction of carbon emissions, and a reduction of pollution [5]. Densley Tingley [6] estimated that a $49 \%$ saving in embodied carbon is accomplished by DfD. A social benefit of DfD is creating jobs for unskilled workers, and economic benefits are, amongst others, the creation of a new market for salvage materials and cost reduction [7]. Other benefits of DfD and the reuse of building materials are, for example, the historic preservation of building elements and obtaining credits in building assessment systems.

Within architecture, DfD was articulated by Jean Prouvé in his design for a Tropical House in 1949 [8] or by Rural Studio [9]. The fact that DfD has gained increasing attention lately is mainly due to the increasing interest in the Circular Economy: An economic model that gradually decouples economic activity from the consumption of finite resources and aims to design waste out of the system. The circular economy model divides materials into two categories: Products from the biosphere and technical materials. The majority of building materials fits well in the latter category. In the circular economy, technical materials are expected to be (1) shared, (2) maintained, (3) reused, (4) refurbished, and (5) recycled (in order of importance) [10]. A similar approach was specified in the Waste Framework Directive of the European union, which has defined the waste hierarchy to be (1) prevention, (2) reuse, (3) recycling, (4) recovery for other purposes, such as energy, and (5) disposal [11]. Both prevention and reuse of materials are regarded as high priority, which is the core of DfD.

Today, less than $1 \%$ of existing buildings are fully demountable [12] and design for deconstruction is not a mainstream concept. A major problem for DfDand 'circular planning' may be the nature of building projects, since they normally have a start and an end [13]. It might also require a fundamental change of the architects' perception of buildings as defined by Durmisevic and Yeang [14]; (1) buildings should not be conceived as static structures, but as dynamic and open ones that can easily adapt to changing requirements; (2) the transformation capacity of buildings and systems needs to be extended by considering the whole life cycle of the building and building systems; (3) treat building materials as long-term valuable assets through their whole life cycle using reconfiguration, reuse, and remanufacturing options at the building, system, and material levels; (4) consider waste and demolition as a design error; (5) decouple the fixed function-material relationship in buildings via the design of reconfigurable systems; and (6) involve the construction industry in the whole life cycle of the building and building systems.

Although previous literature has focused on design for deconstruction, today, DfD is not mainstream in the building industry. In order to understand the underlying reason, the aim of this literature review was to study the state-of-art of design for deconstruction and the impact on the design process of buildings by reviewing scientific articles, existing guidelines, and standard practices in the building industry. The focus on the effect of DfD on the design process meant that the energy and environmental aspect of reusing building materials are not specifically studied in this review.

\section{Method}

This literature review was performed in three steps: (1) A scientific article review, (2) a professional guideline and common practice review, and (3) the categorisation of the results. The theme of DfD is closely related to many research areas, for example, Life Cycle Analyses (LCA), reuse of building materials (but not specifically designing for the deconstruction of it), energy use in buildings, building materials, etc. (Figure 1). For this literature review of scientific articles and the professional guidelines in this study, it was important to filter out those articles and guidelines that were not directly focusing on the design process. 


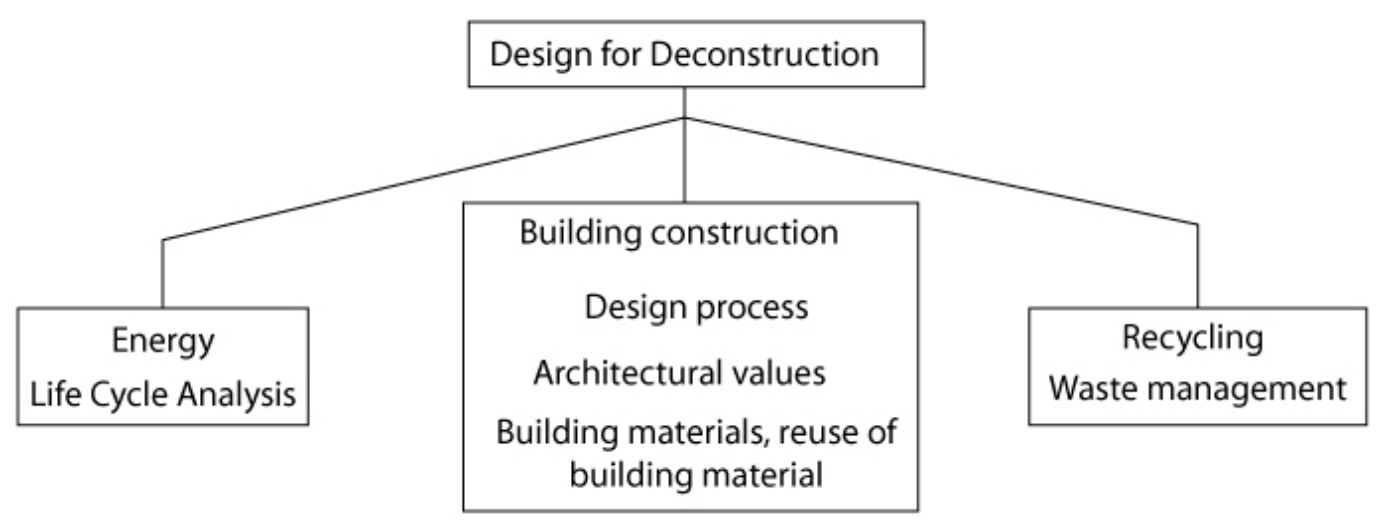

Figure 1. Design for deconstruction and related themes.

\subsection{Scientific Article Review}

To find relevant publications, a two-step literature search was conducted in June 2018. The used source was the internet platform LUBsearch [15], a search engine provided by Lund University. This search engine is connected to several databases, amongst them Scopus, Web of Science, IEEE, JStor, ScienceDirect, and EBSCOHost.

In previous literature, both terms design for deconstruction and design for disassembly were used; therefore, the following two search words were used:

- $\quad$ Search 1: Keywords: "design for deconstruction" and building in academic journals.

After searching, 64 records were identified. Duplicates were removed $(n=50)$. Then, records were screened by reviewing the abstract, and articles were omitted if the content of the abstract and articles was too specific and not focused on the design process $(n=34)$. Then, full-text articles were assessed for eligibility and those that also did not focus on the design process were omitted. In total, 10 studies were included in the synthesis.

- $\quad$ Search 2: Keywords: "design for disassembly" and building in academic journals.

After searching, 86 hits were identified. The same procedure here was applied as in search 1, leading to eight studies to be included in the final synthesis.

\subsection{Professional Guidelines and Common Practice Review}

In addition to the search for scientific literature, a search on the internet was performed for architectural practices and other professional websites that relate to the field of architecture. In total, only two sources were found eligible for a focus on DfD and the design process.

Additionally, the Swedish Association of Architects was contacted to find additional sources for professional guidelines.

\section{Results}

The majority of the reviewed scientific articles and guidelines from the profession introduced the area of design for deconstruction from the angle of environmental benefits. From the reviewed articles the following categories were identified as important:

1. General design and construction principles

2. Specific materials' potential for DfD

3. DfD throughout the design process

4. Tools for DfD

5. Existing building stock potential

6. Barriers and drivers for DfD 
In the subsections below, these categories will be discussed. Figure 2 provides an overview of the mentioned categories.

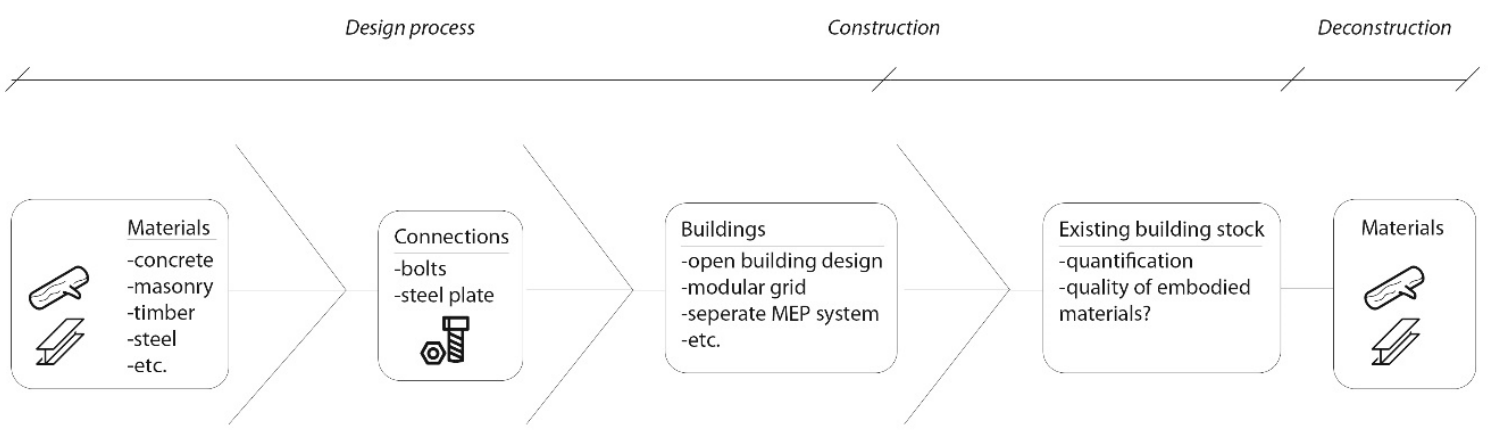

Figure 2. Mentioned categories in literature.

\subsection{General Design and Construction Principles}

The majority of the reviewed articles and professional guidelines mentioned a set of general design and construction principles. There is no internationally agreed definition on design for deconstruction and neither are there-as far as the author's knowledge-any requirements on the use of DfD principles in the building code in any country. In many of the reviewed documents, the following themes were mentioned: (a) Overall building design, (b) Materials and connections, (c) Construction and deconstruction phase, (d) Communication, competence, and knowledge in the design process.

(A) Overall building Design

The whole building design has a large impact on the potential for design for deconstruction. The following design principles for building design in relation to DfD were identified:

A1. Use a simple, modular design $[5,16]$.

A2. Use an open, flexible building system that is allows the functions to change in the future $[5,6,16,17]$. A3. Use a modular structural grid $[5,6,16]$.

A4. Design building so elements are layered according to their anticipated lifespan [6,16,17].

A5. Make sure stability is maintained during deconstruction [17].

A6. Separate mechanical, electrical and plumbing (MEP) systems [18].

Not only do these building design principles facilitate the deconstruction of the building, they will also allow for adaptive reuse of the building (the reuse of a building for another purpose than it was meant for) which will allow for a prolonged use of a building.

Although it was mentioned that the design of the building should preferably be modular and simple, and despite the fact that complex shapes could complicate the deconstruction of building materials and components, this does not necessarily mean it will lead to less architectural freedom for architects.

(B) Materials and connections

Selecting the right materials, connections, and components for DfD is probably the most important design aspect for the design team for achieving a high degree of DfD. The following main principles concerning materials and connections were mentioned in the literature:

B1. Minimise the number of different materials, connections and components $[5,6,16]$.

B2. Design joints that are accessible and durable [6,16-19].

B3. Use mechanical joints (bolts, nuts) instead of other types of joints [5,16-18].

B4. Use nontoxic, noncomposite, durable, and high-quality materials that can be reused [5,16-19].

B5. Avoid use of binders, adhesive, resin, and secondary finishes [5,6,16,17]. 
B6. Use recycled and recyclable materials [16].

B7. Use lightweight materials [16].

For every building, the design team needs to think about materials and connections. Applying DfD principles in the design of the building will require additional competence about designing connections that can be reversed.

\section{(C) Construction and Deconstruction Phase}

The majority of the building stock is planned to stand for a considerable amount of time, while the end-of-life of a building is normally not considered. While DfD, it is obvious that not only the construction phase is important, but also the reverse construction in the deconstruction phase. In literature, the following main principles regarding the construction and deconstruction phase are mentioned:

C1. Develop and design a deconstruction plan already in the design process [6,17].

C2. Use prefabricated components and materials $[16,17,20]$.

C3. Make sure components are sized to suit handling [16,18].

C4. Deconstruction should be possible with common tools and equipment $[5,16]$.

C5. Allow for parallel disassembly [16].

C6. Ensure access to building components [19].

The implications of these main principles are mainly on how the physical deconstruction will take place, using common available tools and with components that have a reasonable size. Prefabrication will ease the construction of dry joint connections [20].

(D) Communication, Competence, and Knowledge

DfDwill have an impact on the design process, the communication between key players, needed competence, and knowledge. In the reviewed literature, the following main principles are mentioned:

D1. Information, documentation about used materials, and deconstruction method (and as-built drawings) need to be stored $[6,16,19]$.

D2. Component types should be identifiable $[6,16]$.

D3. Material types should be identifiable $[16,21]$.

D4. The design team needs to the right competence, training, and will to work with design for deconstruction $[5,6]$.

The identification of materials is also discussed by Iacovidou, Purnell, and Lim [21], who propose the use of smart technology (radio-frequency identification). Such an identification enables to look at more specific details of materials rather than relying on 'as-built' drawings.

\section{Closed-loop}

A related concept to design for deconstruction is to design for closed-loop materials. Sanchez and Haas [13] performed a literature study about project planning for the circular economy. According to these authors, it is important to consider closed-loop principals; a construction that involves recycling or reusing building materials and components from older buildings through natural or industrial processes. The promotion of closed-loop material use maximises the use of resources. Some building materials are more beneficial for this, like steel. When extracting materials from older buildings, it is also critical to have an accurate inventory of existing buildings), because it will maximise the project's financial, environmental, and social performance. They also found that, when reusing building materials, costs shift; material costs were significantly lower, labour costs higher.

Kibert [22] defined that an effective strategy for the use of closed-loop building material and require that (1) a building must be fully deconstructible; (2) a building must be disassemblable; 
(3) construction materials must be recyclable; (4) the production and use of materials must be harmless; and (5) the material generated as a result of the recycling process must be harmless.

\subsection{Specific Material Potential for DfD}

The reuse of material normally extends only the lifespan of the material, while the material loop remains linear rather than cyclical [19]. Timber and steel were considered as closed-loop cycle materials because they can be processed in an infinite cycle. Foundations were found hard to be constructed with CLC materials as well as plasterboard, which was assessed to have low recyclability and often encounters problems with demountability. Further, masonry elements, roof tiles, and thermosetting plastic insulation materials are hard to consider as CLC materials.

Densley Tingley [6] studied the deconstruction feasibility of specific construction materials; timber, masonry, concrete, and steel.

When it comes to timber, Densley Tingley [6] stated that structural timber is not always reused as structural timber, but is used for other purposes. Older timber structures are considered to be ideal for deconstruction, mainly because they use simple construction techniques and come in standard sizes. An important factor regarding the deconstruction of timber is the used type of jointing, where the use of bolts or metal plate connectors is ideal.

When it comes to masonry, bricks and blocks are generally made in standard sizes, which is considered to be convenient for reuse. Here, an important factor is the fixing of the bricks and blocks, where lime mortar is easier to separate and clean, while cement mortar (mainly used nowadays) makes it difficult to separate.

Concrete is considered by Densley Tingley [6] to be a difficult material for deconstruction if it is not specifically designed for it. Especially reinforced concrete structures are not suitable for deconstruction. Jointing with other material is often by means of cement, making it hard to reuse.

Steel is often not reused, but is recycled to a high extent. Reusing steel depends mainly on the used steel quality, but also on the connection method (where bolts are preferred). Additionally, the addition of fire protection around steel could make deconstruction harder.

\subsection{DfD Throughout the Design Proces}

Design for deconstruction needs to be considered in each stage of the design process [18]. Guy and Ciarimboli identified the following considerations:

1. The predesign phase, where interior elements, service system, and structure can be designed in such a way that future modifications are possible. It is also important that the involved key players are flexible: A fixed brief, for example, will limit the building's future use, while working with scenarios might open up for solutions that will prolong the building's life.

2. In the concept design phase, the designer together with contractor meets with vendors to identify reused materials which support DfD.

3. In the schematic design, the first design is checked by producing a plan to deconstruct the building.

4. In the design development phase, a detailed plan for the deconstruction of the building is carried out.

5. In the construction documents, it should be insured that details do not compromise their DfD integrity. Further, bid documents should reflect the commitment to a DfD construction.

6. For the construction administration, as set of 'as-built' documents should be created.

7. The facility operation services should brief all maintenance staff on the DfD strategy of the building.

Guy and Ciarimboli [18] also described which elements the deconstruction plan, as mentioned as number 3 in the list above, should contain: 
(a) A statement of the chosen strategy for DfD related to the building;

(b) A list of building elements, normally embedded in 'as-built' drawings. In the future, Radio Frequency ID (RFID) identification tags could take over the drawings;

(c) Instructions on how to deconstruct elements;

(d) Distribution of DfD plans.

\subsection{Tools for $D f D$}

Currently, there are not many tools on the market that support the design team to design for deconstruction. At the same time, the rise of Building Information Modelling (BIM) in the construction sector is noticeable: In 2017, more than $60 \%$ of the architectural practices in the UK used BIM [23]. Such a BIM model does not only contain a 3D specification of the geometry and its location in the building, but it can also contain additional information about the used materials.

The development of BIM evolves from a platform to store and model a 3D towards a more sophisticated model, where different actors can schedule projects (BIM 4D), estimate costs (BIM 5D), focus on sustainability (BIM 6D), and where the facility management in controlled (BIM 7D) [24]. Especially BIM 7D has clear benefits for DfD, because it has detailed information on, for instance, material specifications, time of the next maintenance, exact location for each building embedded element, etc. Therefore, BIM can play an important role in the development of DfD tools.

Akinade et al. [25] developed and presented a BIM-based tool for deconstruction. It is based upon a mathematical model describing, for instance, the set of materials, components, and connectors; how and if they are reusable, etc. By assigning a certain Deconstructability Assessment Score (BIM-DAS), they described a model to determine the extent to which a building could be deconstructed right from the design stage.

Akinade et al. [26] assessed existing DfD tools and identified essential functionalities of a BIM-based tool for DfD. By conducting focus group interviews, they identified seven key functionalities: (i) Improved stakeholders' collaboration, (ii) visualisation of deconstruction process, (iii) identification of recoverable materials, (iv) deconstruction plan development, (v) performance analysis and simulation of end-of-life alternatives, (vi) improved building whole life management, and (vii) interoperability with existing BIM software.

\subsection{Existing Building Stock Potential for DfD}

Not only is DfD not considered when designing new buildings, this is also true for the existing building stock, of which less than $1 \%$ is fully demountable today [12]. While the reuse of building materials, without considering the deconstruction of such materials, was not the focus of this literature review, it was mentioned by Crowther [16] that reused building materials could be used in DfD. This leads to the question what the 'mining' potential of the current building stock is.

Robust and reliable data for outflows from the construction sector are hard to find, and only in rare cases are national demolition data collected [27]. Stephan and Athanassiadis [28] developed a method to quantify and map the embodied energy in the existing building stock of a city. They demonstrated the method by studying the city of Melbourne, Australia. From every building, the geometry is modelled and a bill of quantities is derived. By matching this with known construction assemblies from different types of buildings and construction year, it was possible to calculate the total amount of materials within the city boundaries. Then, for every material, the embodied energy was calculated. By applying it to the whole city scale, it reveals the significant amounts of embodied materials in our buildings.

A similar approach was taken by Mastrucci et al. [29], who described a method that not only produced a bill of materials for a city in Luxemburg, but also performed an LCA assessment at the urban scale, thereby considering different end-of-life (EoL) options. However, reuse was not considered to be an EoL option. 
It is however crucial to understand to which extent these embodied materials are extractable. This is determined by many parameters, e.g., what is the quality of the materials, how is it connected to the rest of the building, what is the anticipated life span, etc. A parallel can be made with the Deconstructability Assessment Score as described by Akinade et al. [25].

\subsection{Barriers and Drivers for $D f D$}

Only two studies looked into the potential barriers and drivers for DfD.

Akinade et al. [5] defined the following possible barriers for DfD:

- Lack of technical knowledge and supporting tools;

- Belief that end-of-life may not occur for a long period;

- Value of building materials and components of EoL is not guaranteed.

Rios, Chong and Grau [7] defined the following barriers:

- Uncertainty of the quantity and quality of the used material;

- Lack of rules and standards related to the construction with such materials;

- Components might get damaged on-site during deconstruction;

- Common negative perception by the end user of reused materials;

- Designer and constructors conceive their design to be permanent;

- Time constraints due to the fact that disassembly might take significantly more time than mechanical demolition;

- Costs constraints due to the perception that deconstruction costs more than demolition and disposal, which is not always true;

- Contract constraints that could make reuse less feasible;

- Lack of involvement to minimise waste amongst manufacturers;

- Lack of accounting methods for the measuring the benefits of DfD.

Both studies [5,7] identified stricter legislation and policies to be a key driver for DfD. Furthermore, Akinade et al. [5] identified the use of BIM, improved education for architects and design engineers, as well as more points in sustainability guidelines, for example, Breeam and LEED, as other key drivers for DfD.

\section{Discussion}

DfD can lead to environmental, social, and financial benefits. It also has a significant effect on how buildings are designed and constructed.

\subsection{Environmental Benefits}

Extending the use of building material is considered to be beneficial from an environmental perspective, because it saves the use of virgin raw materials and embodied energy for producing these building materials. This is particularly true when high-quality building materials are used for the first cycle and when the second cycle starts rather soon after the first cycle. With stricter building regulations, for instance on the average U-value of the construction as specified in the Swedish building regulations [30], it will be very hard to comply with these rules if a high amount of reused building materials and components is used, simply because the energy performance of reused building components is lower than newer similar components. This is particularly true for insulation materials, where its lifespan is predicted to be 30 years, making the reuse of such materials difficult.

Another factor regarding the environmental impact and design for deconstruction is the fact that it affects the energy use of the operational phase. If the energy performance of the building envelope decreases because of a high share of reused building materials and components (and thus often lower quality), it might result in an increase in operational energy use. If the total environmental footprint of 
the building is calculated, including production and operational phase, then the embodied energy of the materials and components is decisive, as well as the environmental footprint of the energy mix of the location where the building is located. The balance between the two factors is very location-dependent and might determine if the reuse of building materials is environmentally beneficial.

\subsection{Financial Benefits}

DfD will require more effort in the design process, leading to more upfront costs. On the other hand, a carefully designed building for deconstruction might also be financially beneficial, because at the end of the first cycle, building materials and components might get sold. This also depends on the market of salvaged building materials, which is not mature yet. An assessment of the financial benefit of DfD is not always straightforward to calculate, because the additional labour costs, savings of building materials, etc. are hard to predict before the building is actually constructed and experiences and lessons learned from previous buildings with reused building materials are not widespread.

\subsection{The Effect on Architecture and the Design Process}

Architects and engineers in the design team might consider DfD as an extra constraint on the design process.

It is important that architects and other members of the design team experience DfD not as a constraint, but as an additional element that can enrich the design process.

The shift towards the Integrated Design Process-where more expertise is shifted from the later design stages towards the early stages-has proven to make the design of energy-efficient building easier [31]. A similar approach for DfD can be applied here, too, where the focus on DfD in the early design stage already will not only minimise the cost of demolition later, but could also generate revenue from the waste stream if connections and components were designed in such a way that they still remain mainly intact.

\section{4. (De-)Construction}

In literature, prefabrication is mentioned as one way to ease the construction for connections and components that can be deconstructed. In the prefabrication assembly line, a high level of accuracy can be obtained, as well as specialised tools that can be used indoors.

Another factor that affects the deconstruction of built-in materials is how the building is maintained. This has a significant impact on the state of the materials after each cycle.

\subsection{Temporary Structures as Testbed for Design for Deconstruction}

DfD principles could be implemented in buildings of temporary character, for instance pavilions, stages, barracks, etc. In many countries, such temporary buildings have less strict building regulations and are of a smaller scale. These two conditions will help to test how such temporary structures can be designed for deconstruction, built, and deconstructed and will help to identify which materials and construction methods are most suitable for deconstruction. One example of testing such a new design process and workflow was visible in the People's pavilion of the Dutch architecture office Bureau SLA and Overtreders W (Figure 3). In this pavilion, all building materials were borrowed, either from residents or from companies [32]. 


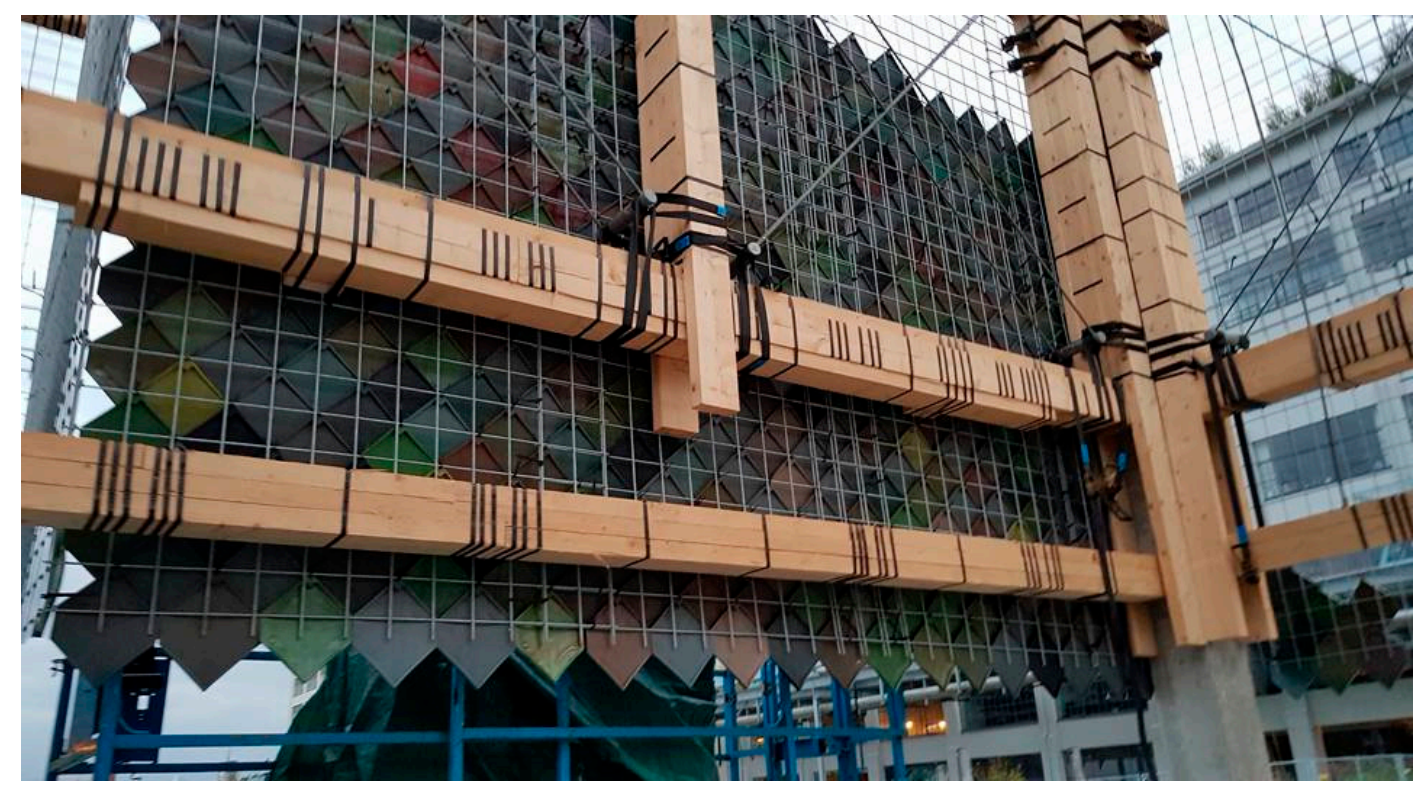

Figure 3. Detail of the People Pavillion, Eindhoven. Photo @ Marcel Schneijdenberg.

\section{Conclusions}

In this paper, a literature review of the current state of the art of design for deconstruction is presented, with a focus on the impact on the design process. For the literature study, two sources were used: Scientific articles and guidelines from the profession. The reviewed articles and guidelines were categorised into the following themes: (1) General design and construction principles, (2) specific materials' potential for DfD, (3) DfD throughout the design process, (4) tools for DfD, (5) existing building stock potential, and (6) barriers and drivers for DfD.

This study has shown that there is a lack of an internationally agreed set of guidelines for the design team for design for deconstruction, although various key aspects are mentioned, like the effect of the overall building design, design of connections and materials, and the need for a preparation for the deconstruction phase. When it comes to the design process, DfD has to be considered already in the early design stage. Throughout the later design process, the level of detail of the deconstruction process increases and should result in a deconstruction plan, as-built drawings, or a similar BIM model. Although there is significant amount of literature and professional guidelines on design for deconstruction, its implementation on the routines of the design team has proven to be limited.

Furthermore, different building materials have a different potential for deconstruction. Gaining knowledge about the advantages and disadvantages of different building materials is a key for the design team. Although it is a challenge to find new ways of using those materials that are hard to reuse, it might open up new possibilities when DfD.

There are currently not that many tools available to support the design team for DfD. The increasing use of BIM can encourage DfD because of its ability to store which elements are present in the building, as well as their location, properties, etc.

The potential of the existing stock is yet rather unexploited as a source of building materials for DfD. Some methods for quantifying the potential of embodied materials exist, but are not yet fully available and widespread. Those methods mainly assess the quantity of the embodied materials, but do not assess the quality of the materials—a factor that is decisive for the possible reuse of building materials and components.

The main barriers for DfD were identified as the lack of legislation and the time and cost constraints for the design team and the client. A more flexible legislation that tolerates the reuse of building materials might accelerate the design for deconstruction as a principle in the design 
process. Describing the potential environmental and financial benefits of DfD for future clients will also stimulate the demand for DfD in the design process.

\section{Future Research}

Future research should focus on the question of whether DfD limits the architectural expression or if it could be considered as opening up new possibilities for architecture. More and more projects are now built where reused building materials are used as architectural elements and where the reuse was the core of the architectural concept of the building.

An increase of DfD in the building design process will also require additional research on how a real design process looks like when architects and a design team design for deconstruction. What should also be studied is which competence is needed.

Funding: This research received no external funding.

Acknowledgments: The author would like to thank the department of Architecture and Built Environment at Lund University for the possibility to perform this study

Conflicts of Interest: The author declares no conflict of interest.

\section{References}

1. Swedish Energy Agency. Energiläget 2017; Swedish Energy Agency: Stockholm, Sweden, 2017.

2. Liljenström, C.; Malmqvist, T.; Erlandsson, M.; Fredén, J.; Adolfsson, I.; Adolfsson, I. Byggrroduktionens miljöpåverkan i förhållande till driften Livscykelberäkning av klimatpåverkan och energianvändning av ett nyproducerat flerbostadshus i betong med lågenergiprofil Byggproduktionens miljöpåverkan i förhållande till driften Livscykelberäkn; KTH: Stockholm, Sweden, 2014.

3. Hradil, P. Barriers and Opportunities of Structural Elements Re-Use; European Commission: Brussels, Belgium; Luxembourg, 2012.

4. Swedish Environmental Protection Agency. Avfall i Sverige 2016; Swedish Environmental Protection Agency: Stockholm, Sweden, 2018.

5. $\quad$ Akinade, O.O.; Oyedele, L.O.; Ajayi, S.O.; Bilal, M.; Alaka, H.A.; Owolabi, H.A.; Bello, S.A.; Jaiyeoba, B.E.; Kadiri, K.O. Design for Deconstruction (DfD): Critical success factors for diverting end-of-life waste from landfills. Waste Manag. 2017, 60, 3-13. [CrossRef] [PubMed]

6. Densley Tingley, D. Design for Deconstruction: An Appraisal; University of Sheffield: Sheffield, UK, 2012.

7. Rios, F.C.; Chong, W.K.; Grau, D. Design for Disassembly and Deconstruction-Challenges and Opportunities. Procedia Eng. 2015, 118, 1296-1304. [CrossRef]

8. Prouvé, J.; Cinqualbre, O. Jean Prouvé: La Maison Tropicale = The Tropical House; Centre Pompidou: Paris, France, 2009.

9. Dean, A.O.; Hursley, T. Rural Studio: Samuel Mockbee and An Architecture of Decency; Princeton Architectural Press: New York, NY, USA, 2002.

10. Ellen Macarthur Foundation. Growth Within: A Circular Economy Vision for a Competitive Europe; Ellen Macarthur Foundation: Cowes, UK, 2015.

11. European Parliament and European Council. Directive on Waste; European Union: Brussels, Belgium, 2008.

12. Chini, A.; Schultmann, F. Design for Deconstruction and Materials Reuse; CIB World: Karlsruhe, Germany, 2002.

13. Sanchez, B.; Haas, C. Capital project planning for a circular economy. Constr. Manag. Econ. 2018, 36, 303-312. [CrossRef]

14. Durmisevic, E.; Yeang, K. Designing for Disassembly (DfD). Archit. Des. 2009, 79, 134-137. [CrossRef]

15. I. EBSCO Industries, "LUBsearch," 2018. Available online: https://www.lub.lu.se/sok/lubsearch (accessed on 3 November 2018).

16. Crowther, P. Design for Disassembly—Themes and Principles; RAIA/BDP Environment Design Guide; The Royal Australian Institute of Architects: Queentown, Australia, 2005.

17. Guldager Jensen, K.; Sommer, J. Building a Circular Future; 3XN: Copenhagen, Denmark, 2016.

18. Guy, B.; Ciarimboli, N. Design for Disassembly in the Built Environment: A Guide to Closed-Loop Design and Building; Pennsylvania State University: University Park, PA, USA, 2006. 
19. Sassi, P. Defining closed-loop material cycle construction. Build. Res. Inf. 2008, 36, 509-519. [CrossRef]

20. Jaillon, L.; Poon, C. Design issues of using prefabrication in Hong Kong building construction. Constr. Manag. Econ. 2010, 28, 1025-1042. [CrossRef]

21. Iacovidou, E.; Purnell, P.; Lim, M.K. The use of smart technologies in enabling construction components reuse: A viable method or a problem creating solution? J. Environ. Manag. 2018, 216, 214-223. [CrossRef] [PubMed]

22. Kibert, C.J. Sustainable Construction: Green Building Design and Delivery; Wiley: Hoboken, NJ, USA, 2016.

23. National Building Specification. National BIM Report 2017; RIBA Enterprise: Newcastle, UK, 2017.

24. Czmoch, I.; Pękala, A. Traditional Design versus BIM Based Design. Procedia Eng. 2014, 91, $210-215$. [CrossRef]

25. Akinade, O.O.; Oyedele, L.O.; Bilal, M.; Ajayi, S.O.; Owolabi, H.A.; Alaka, H.A.; Bello, S.A. Waste minimisation through deconstruction: A BIM based Deconstructability Assessment Score (BIM-DAS). Resour. Conserv. Recycl. 2015, 105, 167-176. [CrossRef]

26. Akinade, O.O.; Oyedele, L.O.; Omoteso, K.; Ajayi, S.O.; Bilal, M.; Owolabi, H.A.; Alaka, H.A.; Ayris, L.; Looney, J.H. BIM-based deconstruction tool: Towards essential functionalities. Int. J. Sustain. Built Environ. 2017, 6, 60-271. [CrossRef]

27. Miatto, A.; Schandl, H.; Tanikawa, H. How important are realistic building lifespan assumptions for material stock and demolition waste accounts? Resour. Conserv. Recycl. 2017, 122, 143-154. [CrossRef]

28. Stephan, A.; Athanassiadis, A. Quantifying and mapping embodied environmental requirements of urban building stocks. Build. Environ. 2017, 114, 187-202. [CrossRef]

29. Mastrucci, A.; Marvuglia, A.; Popovici, E.; Leopold, U.; Benetto, E. Geospatial characterization of building material stocks for the life cycle assessment of end-of-life scenarios at the urban scale. Resour. Conserv. Recycl. 2017, 123, 54-66. [CrossRef]

30. Swedish National Board of Housing, Building and Planning; Swedish Building Code BBR; National Board of Housing, Building and Planning: Boverket, Sweden, 2016.

31. Kanters, J.; Horvat, M. The design process known as IDP: A discussion. Energy Procedia 2012, 30, $1153-1162$. [CrossRef]

32. Bureau SLA, "People's Pavilion," 2017. Available online: http://www.bureausla.nl/project/peoplespavilion/ (accessed on 3 November 2018).

(C) 2018 by the author. Licensee MDPI, Basel, Switzerland. This article is an open access article distributed under the terms and conditions of the Creative Commons Attribution (CC BY) license (http://creativecommons.org/licenses/by/4.0/). 